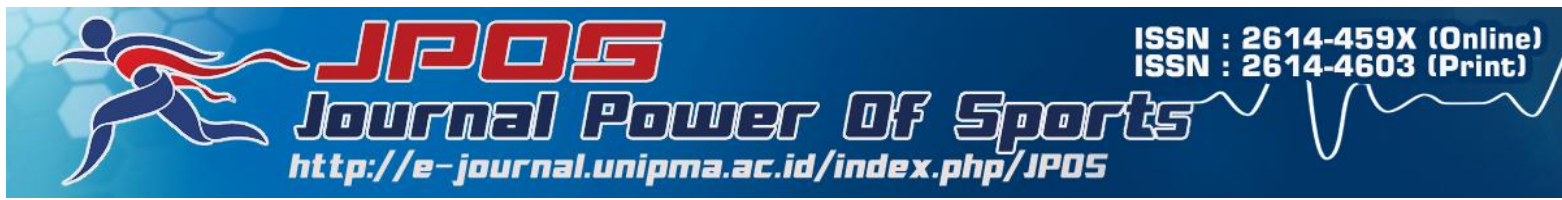

\title{
Pengaruh latihan bosu ball pistol squats dan single leg $R D L$ with press terhadap keseimbangan atlet poomsae taekwondo
}

\author{
Setiyawan \\ Program Studi Pendidikan Jasmani Kesehatan dan Rekreasi, Universitas PGRI Semarang, \\ Indonesia \\ Email: setiyawan@upgris.ac.id
}

Received: 12 Juli 2018. Accepted: 29 Agustus 2018. Published: 31 Agustus 2018

\begin{abstract}
Abstrak
Penelitian ini bertujuan untuk mengetahui pengaruh latihan bosu ball pistol squats dan single leg RDL with press terhadap keseimbangan atlet poomsae Taekwondo dan sebagai inovasi dan masukan untuk pelatih taekwondo dalam latihan keseimbangan pada poomsae Taekwondo. Penelitian ini menggunakan quasi eksperimen Two Groups Pretest-Posttest Design, dengan membagi menjadi dua kelompok, kelompok A dengan perlakuan latihan bosu ball pistol squats, sedangkan untuk kelompok B dengan latihan single leg RDL with press. Populasi dalam penelitian ini adalah keseluruhan dari atlet poomsae UKM Universitas PGRI Semarang dengan total populasi 30 orang. Teknik sampling menggunakan purposive sampling dan sampel yang terpilih berjumlah 16 orang atlet putra dengan pembagian sampel secara ordinal pairing. Instrumen yang digunakan adalah tes keseimbangan menggunakan Balance Measuring Instrument. Analisis data mengunakan pada penelitian ini menggunakan uji t. Hasil pengujian data menunjukkan adanya pengaruh yaitu peningkatan keseimbangan pada kelompok bosu ball pistol squats dengan peningkatan $37.97 \%$, dengan signifikasi pada kelompok bosu ball pistol squats dengan t hitung 11.237> 2.36 (t-tabel). Hasil kelompok dengan latihan single leg RDL with press memperlihatkan peningkatan sebesar $31.21 \%$, dengan t hitung 5.835> 2.36 (t-tabel). Metode latihan bosu ball pistol squats lebih baik daripada metode latihan single leg RDL with press dalam meningkatkan keseimbangan atlet poomsae taekwondo.
\end{abstract}

Kata Kunci: Metode latihan; keseimbangan; taekwondo.

\section{Abstract}

This research aims to know the influence of the bosu exercise ball pistol squats and single leg RDL with the press against the balance of poomsae Taekwondo athlete and as an input to innovation and taekwondo coaches in training balance on the poomsae Taekwondo. This research uses quasi experiment Two Groups Pretest-Posttest Design, by dividing into two groups, Group A with bosu ball exercise treatment pistol squats, while for the Group B with single leg RDL with press. The population in this research is a whole of Jocks poomsae SME University PGRI in Semarang with a total population of 30 people. The sampling 
technique using purposive sampling and sample selected 16 athletes totaled son with the Division of the sample are ordinal pairing. The instruments used are a test of balance using Balance Measuring Instrument. Data analysis using this research on using test $t$. test results data indicate the presence of influence, namely an increase in the balance on bosu ball pistol squats with increased $37.97 \%$, with the significance of the bosu ball pistol squats with $t$ calculate 11,237 > 2.36 ( $t$-table). The results of the exercise group with single leg RDL with the press showed an increase of 31.21\%, t count 5,835 > 2.36 (t-table). Bosu ball exercise method pistol squats exercise method is better than the single leg RDL with press in taekwondo poomsae athletes improve balance

Keyword: Exercise; balance; taekwondo.

How To Cite : Setiyawan. (2018). Pengaruh latihan bosu ball pistol squats dan single leg to APA Style RDL with press terhadap keseimbangan atlet poomsae taekwondo. JPOS (Journal Power Of Sports), 1 (2), 42-50.

\section{PENDAHULUAN}

Semua aspek dalam kehidupan manusia pasti mempunyai tujuan seperti apa yang menjadi target dan cita-cita. Tujuan tersebut bisa merupakan tujuan yang akan dicapai dalam jangka waktu panjang maupun dalam jangka waktu yang pendek. (Setiyawan, 2017: 1). Salah satu tujuan yang akan dicapai suatu negara bisa melalui prestasi olahraga. Prestasi olahraga sebuah negara menjadi salah satu tolak ukur kualitas SDM yang ada di negara tersebut. Faktor keberhasilan pencapaian prestasi atlet olahraga antara lain faktor atlet, kualitas latihan, ketersediaan sarana dan prasarana serta faktor penunjang lainnya. Menurut Djoko Pekik Irianto (2002: 27) suatu prestasi dicabang olahraga tidak bisa datang secara cepat dan instan, perlu adanya tahapan yang jelas dalam pembinaan mulai dari usia dini. Pembinaan diolahraga prestasi memiliki tahapan-tahapan pembinaan, yaitu (1) tahap pemassalan, (2) tahap pembibitan atlet, dan (3) tahap pembinaan prestasi. Selanjutnya pada proses tahap latihan

Menurut Djoko Pekik Irianto (2002: 65) komponen fisik merupakan salah satu pondasi utama dari pencapaian prestasi olahraga hal ini dikarenakan teknik, taktik dan mental dapat ditingkatkan dan berkembang dengan baik jika mempunyai kualitas fisik yang cukup baik. Atlet pada cabang olahraga tertentu akan bisa mengembangkan dan meningkatkan keterampilannya dari teknik dasar ke teknik yang lebih lanjut apabila memiliki kemampuan fisik yang baik. Menurut Setiyawan (2017: 2) landasan utama dalam pemilihan calon atlet yang baik adalah potensi kondisi fisik awal yang dimiliki oleh calon atlet, komponen fisik memiliki peran utama dalam proses latihan, dengan memiliki komponen fisik yang baik maka unsur taktik, teknik, dan mental dapat meningkat dan berkembang sejalan dengan proses latihan, apabila kemampuan dalam hal fisik tidak dapat mendukung penampilan atlet maka atlet tersebut tidak dapat menampilkan kemampuan taktik, teknik dan mental yang sampai pada peak performance.

Salah satu cabang olahraga beladiri yang ada di Indonesia adalah taekwondo. Cabang olahraga taekwondo ini merupakan cabang olahraga yang berasal dari semenanjung Korea. Berasal dari tae berarti kaki, kwon yang berarti tangan dan $d o$ yang berarti seni. Taekwondo sendiri memiliki ciri khas yang membedakan dari cabang olahraga beladiri yang lain. Cabang olahraga ini lebih dominan menggunakan kaki sebagai teknik serangan. Taekwondo merupakan salah satu cabang olahraga yang sudah dipertandingkan dalam level kejuaraan daerah, nasional, maupun 
internasional. Level kejuaraan paling tinggi yang mempertandingkan taekwondo adalah even olimpiade. Cabang olahraga beladiri taekwondo dalam pertandingan mempunyai dua nomor pertandingan yaitu nomor kyourugi atau tanding dan poomsae atau seni.

Poomsae atau seni dalam taekwondo merupakan jenis pertandingan dalam taekwondo yang mempertandingkan gerakan atau rangkaian jurus. Menurut (Yoyok Suryadi 2002: 1) definisi poomsae berasal dari rangkaian kata poom dan sae. Dalam hal ini poomsae merupakan sebuah alur gerakan yang terstruktur dalam rangkaian teknik Taekwondo. Poomsae merupakan rangkaian gerakan kombinasi yang disusun untuk latihan dengan atau tanpa pelatih, dengan tetap menggunakan teknik dasar gerakan yang diadopsi dari teknik serangan dan teknik tangkisan. Dengan demikian gerakan poomsae memiliki sebuah keuntungan dalam latihan teknik baru dan mempunyai ciri khusus dari teknik yang sebelumnya. Pertandingan dalam nomor poomsae merupakan pertandingan yang pemenenangnya ditentukan oleh lima atau tujuh orang wasit yang menilai ketepatan, keindahan serta benar tidaknya rangkaian jurus atau seni.

Pada saat ini nomer kategori poomsae menjadi salah satu nomor yang selalu dipertandingkan dalam berbagai macam even. Menjadi seorang atlet poomsae memerlukan komponen fisik dan mental untuk mendukung keberhasilan dalam mencapai prestasi. Hal ini dikarenakan dalam poomsae kesempurnaan gerak yang dinilai oleh karena itu fisik menjadi hal yang penting. Salah satu kompenen yang dibutuhkan dalam poomsae adalah komponen keseimbangan. Keseimbangan merupakan salah satu momok bagi sebagian atlet poomsae. Hal ini diperkuat dengan hasil penelitian Setiyawan (2008) yang meneliti tentang adanya pengaruh keseimbangan terhadap penampilan atet poomsae dimana peningkatan keseimbangan mempengaruhi $33,3 \%$ peningkatan penampilan atlet poomsae. Banyak gerakan dalam poomsae yang memerlukan keseimbangan yang baik. Atlet poomsae harus memiliki tingkat keseimbangan yang baik agar bisa mencapai high level performance.

Keseimbangan dalam hal ini merupakan kemampuan seseorang untuk mempertahankan sikap tubuh yang tepat pada saat melakukan gerakan. Keseimbangan dibagi menjadi dua yaitu: (1) keseimbangan statis, yaitu keseimbangan yang dilakukan ketika posisi tubuh dalam keadaan diam, (2) keseimbangan dinamis yaitu kemampuan untuk bergerak dari satu titik ke titik lain dengan mempertahankan posisi tubuh tetap pada gerakan yang tepat. Menurut Sukadiyanto (2010:136) keseimbangan dipengaruhi oleh kekuatan. Dalam hal ini kekuatan digunakan untuk mengatasi tekanan atau beban yang ditimbulkan dari suatu gerakan. Menurut Sukadiyanto (2010: 136) pengertian kekuatan secara umum adalah kemampuan kontraksi seluruh sistem otot dalam mengatasi tahanan atau beban. Kekuatan/streght adalah unsur dasar biomotor yang ada disetiap berbagai cabang olahraga. Agar bisa mencapai penampilan prestasi puncak, kekuatan harus dikembangkan dan tingkatkan sebagai pondasi awal dalam membentuk komponen unsur biomotor yang lain. Tujuan utama dalam latihan streght adalah meningkatnya daya otot untuk mengatasi tahanan berupa beban maupun gaya ketika melakukan gerakan olahraga.

Dalam olahraga Taekwondo khususnya poomsae kekuatan merupakan landasan penting. Dalam meningkatkan keseimbangan perlu adanya metode latihan yang baik dan dapat secara efektif dan efisien meningkatkan keseimbangan. Metode latihan untuk meningkatkan keseimbangan dalam penelitian ini adalah metode latihan bosu ball pistol squats dan single leg RDL with press yang diterapkan pada program latihan atlet poomsae. Dalam penelitian ini metode bosu ball pistol squats dan single leg RDL with press 
belum pernah menjadi metode latihan dan belum diketahui lebih efektif dan lebih baik mana metode latihan ini untuk meningkatkan keseimbangan atlet poomsae.

\section{METODE PENELITIAN}

Metode penelitian yang digunakan dalam penelitian ini adalah metode quasi experiment (eksperimen semu). Hal ini dikarenakan sampel yang digunakan tidak di control penuh oleh peneliti. Penelitian dengan metode eksperimen/perlakuan bertujuan untuk meneliti adanya hubungan sebab akibat yang dilakukan dengan memberikan satu kelompok atau dua kelompok eksperimen/perlakuan, satu kelompok atau lebih memberikan treatment dan kemudian diperbandingkan hasilnya dengan satu kelompok maupun lebih dari kelompok kontrol yang tidak diberikan kondisi treatment (Narbuko, 2007: 51). Metode eksperimen yang dilakukan pada penelitian ini adalah two experiment groups pretest - posttest design. Dalam penelitian ini sampel dibagi menjadi dua kelompok perlakukan, yaitu kelompok A yang mendapatkan perlakuan metode latihan bosu ball pistol squats dan kelompok B dengan metode latihan single leg RDL with press.

Dalam penelitian ini menggunakan pre test atau tes awal dengan instrumen tes keseimbangan yaitu balance measuring instrument. Pembagian sampel menggunakan ordinal pairing hal ini bertujuan untuk mendapatkan dua kelompok yang mempunyai kesetaraan kemampuan yang sama. Metode ordinal pairing adalah metode yang dalam pelaksanaannya setelah dilakukan tes awal sampel di ranking dan pembagian berdasarkan rumus A-B-B-A. Dalam penelitian ini peringkat satu mendapat kelompok $\mathrm{A}$, urutan kedua $\mathrm{B}$, urutan ketiga $\mathrm{B}$, urutan ke empat $\mathrm{B}$, dan seterusnya.

Tabel 1. Ordinal Pairing

\begin{tabular}{cc}
\hline A & B \\
\hline $1 \rightarrow$ & $2 \downarrow$ \\
$4 \underset{ }{4} \rightarrow$ & $\leftarrow 3$ \\
$8 \rightarrow$ & $\downarrow 6$ \\
$9 \longrightarrow$ & $\leftarrow 7$ \\
\hline
\end{tabular}

\section{Populasi Penelitian dan Sampel Penelitian}

Menurut Sugiyono (2007: 80) populasi merupakan wilayah yang terdiri dari objek/subjek yang mempunyai jumlah dan karakteristik tertentu. Populasi pada penelitian ini adalah seluruh atlet poomsae Universitas PGRI Semarang tahun 2018. Teknik penarikan sampel menggunakan Teknik bersyarat/purposive sampling, teknik untuk penarikan subjek coba yang memakai syarat khusus. Syarat dan pertimbangan penarikan tersebut antara lain: (1) Sudah menggeluti kegiatan dan latihan taekwondo satu tahun, (2)
Taekwondoin poomsae dengan tingkatan umur senior, dan (3) Tidak dalam keadaan sakit. Berdasarkan dari syarat yang ditetapkan sampel yang masuk dalam kriteria berjumlah 16 sampel.

\section{Teknik Pengumpulan Data}

Teknik mendapatkan sumber data yang akan diteliti, maka peneliti memerlukan alat/instrumen untuk penelitian. Tingkat keberhasilan dari sebuah penelitian salah satunya dipengaruhi oleh alat/instrumen yang dipakai. Dalam penelitian ini, alat/instrumen yang digunakan adalah pengukuran keseimbangan yang diukur 
dengan balance measuring instrument.

\section{Teknik Analisis Data}

Data yang terkumpul merupakan hasil tes awal dan tes akhir metode latihan yang diambil dengan tes keseimbangan. Teknik analisis data yang digunakan adalah analisis Uji-t. Sebelum dianalisis dengan Uji t terlebih dahulu dilakukan uji prasyarat analisis

\section{Uji Pra-syarat Analisis}

a. Uji Normalitas

Uji normalitas digunakan untuk pengujian sampel yaitu berhubungan dengan normal atau tidaknya suatu sebaran data yang akan diperoleh kemudian memerlukan analisis. Teknik uji normalitas untuk sebaran data yang diperoleh menggunakan metode Kolmogorov-Smirnov yang menggunakan alat SPSS 20. Dalam Kolmogorov Smirnov, dengan memperhatikan syarat uji:

1) Jika taraf sig di bawah 0,05 mempunyai arti data uji mempunyai perbedaan signifikasi nyata dengan data normal baku, yang mempunyai arti data/hasil hitung tidak bernilai normal.

2) Jika sig berada lebih dari 0,05 maka tidak ada perbedaan yang signifikan nyata antara data uji dengan data normal baku, berarti data/hasil tersebut bernilai normal.

b. Uji Homogenitas

Diperlukan uji homogen data bertujuan untuk menyakinkan bahwa data berasal dari kelompok populasi yang sama/homogen. Uji homogen data menggunakan uji-f berdasar data pre-test dan post-test pada semua kelompok.

\section{Uji Hipotesis}

Uji hipotesis data yang digunakan menggunakan uji t yang diolah dengan SPSS 20 dimana dengan memperbandingkan antara rata-rata kelompok perlakuan dan kelompok kontrol. Dimana jika nilai thitung lebih kecil dari hasil t-tabel, maka Ha di tolak, apabila t-hitung lebih besar daripada t-tabel maka hipotesis Ha diterima.

Agar memasukkan data ke dalam rumus $t$ tes tersebut harus diketahui terlebih dahulu nilai dari mean perbedaan (MD) yang dicari dengan rumus:

\section{Uji Perbedaan Mean (rerata)}

Uji perbedaan mean digunakan untuk mengetahui dan membandingkan peningkatan persentase pada penelitian. Dalam penelitian ini untuk membandingkan presentase peningkatan latihan terhadap keseimbangan dan penampilan. Agar data diketahui prosentase pengaruh setelah dilakukan treatment/perlakuan maka dengan menggunakan perhitungan:

Prosentase hasil beda $=$

Perbedaan rata-rata

Perbedaan Pre-test

x $100 \%$

Mean Different $=$

mean posttest - mean pretest 


\section{HASIL DAN PEMBAHASAN}

Dari hasil penelitian diperoleh data uji normalitas data pada kelompok pre test kelompok A diperoleh nilai $0.995>0.05$ maka data ini berdistribusi normal, kelompok pre test kelompok B 0.977 > 0.05 maka data ini berdistribusi normal, post tes kelompok A $0.951>0.05$ maka data ini berdistribusi normal dan post test kelompok B 0.597> 0.05 maka data ini normal. Maka dapat ditarik kesimpulan bahwa semua data pre test maupun post test berdistribusi normal.

$$
\text { Selanjutnya dilakukan uji }
$$
homogenitas. Data hasil uji homogenitas ditampilkan pada tabel berikut:

Tabel 2. Uji Homogenitas

\begin{tabular}{cccccc}
\hline Kel. & $\begin{array}{c}\text { Levene } \\
\text { statistic }\end{array}$ & $\boldsymbol{d f 1}$ & $\boldsymbol{d f 2}$ & Sig. & Keterangan \\
\hline $\begin{array}{c}\text { Pre-test } \\
\text { A }\end{array}$ & 3.153 & 1 & 14 & 0.097 & Homogen \\
\hline $\begin{array}{c}\text { Pre-test } \\
\text { B }\end{array}$ & 0.028 & 1 & 14 & 0.869 & Homogen \\
\hline $\begin{array}{c}\text { Postest } \\
\text { A }\end{array}$ & 1.849 & 1 & 14 & 0.195 & Homogen \\
\hline Postest B & 0.032 & 1 & 14 & 0.860 & Homogen \\
\hline
\end{tabular}

Keterangan:

Pre-test A:

Pre test kelompok perlakuan latihan bosu ball pistol squats

Pre-test B: Pre test kelompok latihan metode latihan single leg RDL with press.

Post-test A: Post test kelompok perlakuan latihan bosu ball pistol squats

Post-test B: Post test kelompok latihan metode latihan single leg RDL with press.
Dari tabel di atas dapat dilihat distribusi data pre test dan post test kelompok A dan B bernilai homogen dari semua data.

Setelah itu maka dihitung uji beda hasil data pre-test maupun post-test treatment 1 yaitu treatment bosu ball pistol squats yang dapat dilihat pada tabel 3.

Tabel 3. Data deskripsi kelompok A

\begin{tabular}{lrr}
\hline Statistic & \multicolumn{1}{c}{ Pre-test } & \multicolumn{1}{c}{ Post-est } \\
\hline$n$ & 8 & 8 \\
\hline Rata-rata & 45.7500 & 63.1250 \\
\hline Std. Deviation & 14.44942 & 13.73668 \\
\hline Maximum & 71.00 & 88.00 \\
\hline Minimum & 27.00 & 45.00
\end{tabular}




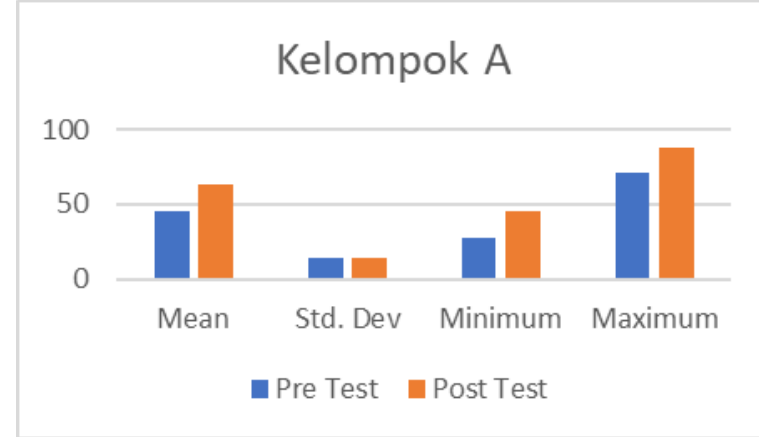

Gambar 1. Data Kelompok A

Perbedaan data rata-rata pre test dan post test data treatment $\mathrm{A}$, di mana ratarata pre test 45.750 sedangkan post-test rata-rata treatment A 63.1250. Data minimum pre-test treatment A 71.00 sedangkan pada post-test nilai maks sebesar 88.00. Ada peningkatan data deskripsi data min pre-test treatment $\mathrm{A}$ yaitu 27.00 dan post-test treatment sebesar 45.00. Kemudian hasil analisis statistik pre-test maupun post-test pada eksperimen B yaitu treatment metode single leg $R D L$ with press dirujuk pada tabel 4.

Tabel 4. Data deskripsi kelompok B

\begin{tabular}{lll}
\hline Statistic & Pre-test & Pos-test \\
\hline$n$ & 8 & 8 \\
\hline Rata-rata & 47.5000 & 60.5000 \\
\hline Std. Deviation & 13.82544 & 9.28901 \\
\hline Minimum & 28.00 & 44.00 \\
\hline Maximum & 70.00 & 75.00
\end{tabular}

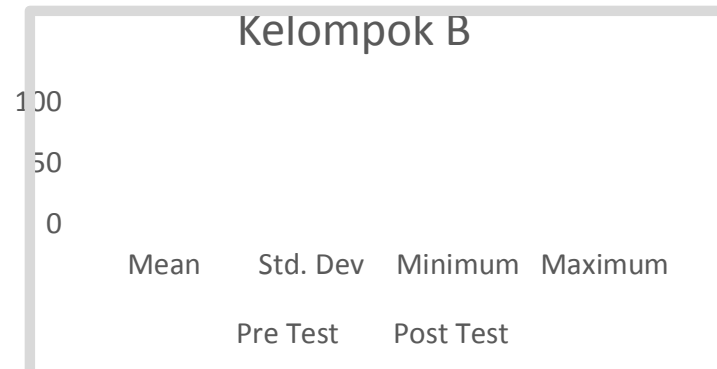

Gambar 2. Data Treatment B

Berdasar data ada beda rata-rata pre-test maupun post-test treatment $\mathrm{B}$, dimana data rata-rata pre-test awal sebesar 47.500 dan post test rata-rata treatment $\mathrm{B}$ sebesar 60.050. Data maks pre test treatment B sebesar 70.00 sedangkan data post-test nilai maks sebesar 75.0 Data min pre-test treatment B yaitu sebesar 28.00 dan post test sebesar 44.0. 


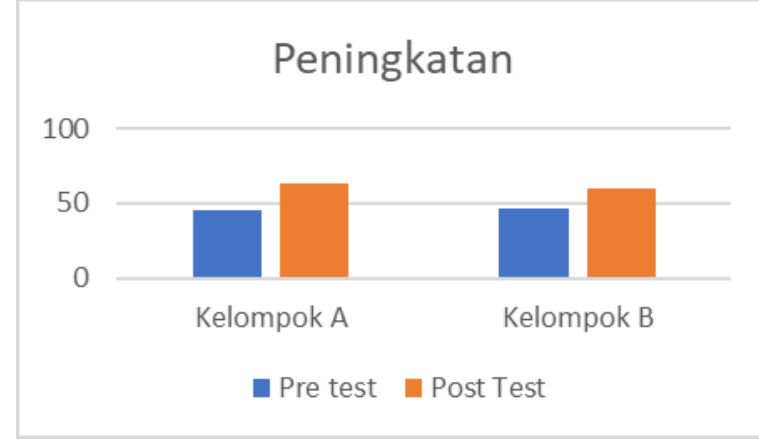

Gambar 3. Peningkatan Perlakuan

Selanjutnya dilakukan analisisa data dengan uji-t. Pengujian berdasarkan data memperlihatkan ada peningkatan keseimbangan pada treatment bosu ball pistol squats dengan peningkatan $37.97 \%$, dengan signifikasi pada kelompok bosu ball pistol squats dengan t hitung 11.237> 2.36 (t-tabel). Hasil kelompok dengan

Latihan single leg RDL with press memperlihatkan peningkatan sebesar $31.21 \%$, dengan $t$ hitung 5.835> $2.36(\mathrm{t}-$ tabel). Dari perbedaan prosentase data ini maka dapat dikatakan metode latihan bosu ball pistol squats lebih baik daripada metode latihan single leg $R D L$ with press dalam meningkatkan keseimbangan atlet poomsae taekwondo.

\section{KESIMPULAN}

Dari hasil penelitian yang sudah dilakukan dapat disimpulkan bahwa latihan dengan metode bosu ball pistol squats dan metode latihan single leg $R D L$ with press dapat meningkatkan keseimbangan pada atlet poomsae taekwondo. Kesimpulan dari penelitian ini adalah:

1. Peningkatan keseimbangan dengan metode latihan bosu ball pistol squats dari penelitian yang sudah dilakukan sebesar $37.97 \%$,

2. Peningkatan keseimbangan dengan metode latihan single leg $R D L$ with press sebesar $31.21 \%$.

\section{DAFTAR PUSTAKA}

Arikunto, S. (2002). Prosedur Prosedur Penelitian: Suatu Pendekatan Praktek. Ed. Rev. VII. Jakarta: Rineka Cipta.

Arikunto, S. (2005). Manajemen Penelitian. Ed Rev VII. Jakarta: Rineka Cipta.

Bompa, T. O. (2000). Theory and Methodology for Young Champions. Champaign II: Human Kinetics.

Cholid, N. (2007). Metodologi Penelitian. Jakarta : Bumi Aksara.

Departemen Pendidikan Nasional. (2000). Pedoman dan Modul Pelatihan Kesehatan Olahraga Bagi Pelatih Olahragawan Pelajar. Jakarta : Pusat Pengembangan Kualitas Jasmani.

Devi, T. (2005). Metode Melatih Teknik dan Taktik Taekwondo. FIK. UNY.

Harsono. (1988). Coaching dan aspekaspek psikologis dalam coaching. Jakarta : Depdikbud

Setiyawan, S. (2017). Kepribadian Atlet Dan Non Atlet. Jendela Olahraga, 2 (1). 
Setiyawan, S. (2017). Visi Pendidikan

Jasmani Dan Olahraga. Jurnal

Ilmiah Penjas, 3 (1).

Sugiyono. (2005). Memahami Penelitian

Kualitatif. Bandung: Alfabeta.

Sugiyono. (2006). Statistika untuk Penelitian. Bandung: Alfabeta.

Sugiyono. (2007). Metode Penelitian Kuantitatif Kualitatif Dan R \& D. Bandung : Alfabeta.

Sukadiyanto. (2002). Teori dan Metodologi Melatih Fisik Petenis". Yogyakarta : FIK-UNY.

Sukadiyanto. (2005). "Pengantar Teori dan Metodologi Melatih Fisik. Yogyakarta : FIK-UNY

Sukadiyanto. (2010). Pengantar Teori dan Metodologi Melatih Fisik. Yogyakarta : FIK-UNY.

Suryadi, Y (2002). Taekwondo Poomase Tegeuk. Jakarta: PT Gramedia Pustaka Utama.

The World Taekwondo Federation. (2004).

Competition Rules \& Interpretation. Jakarta: Komisi Perwasitan PBTI.

The World Taekwondo Federation. (2007). Poomsae Competition Rules \& Interpretation. Jakarta: komisi Perwasitan PBTI. 